\title{
Evaluation of Methods for the Estimation of Threshold Concentrations by the Skin Prick Test
}

\author{
Sten Dreborg ${ }^{\mathrm{a}, \mathrm{b}}$ Margareta Holgersson ${ }^{\mathrm{b}}$ \\ a'Department of Women's and Children's Health, Department of Pediatric Allergology, Uppsala University Hospital, \\ and ${ }^{\text {b }}$ harmacia Diagostics AB, Uppsala, Sweden
}

\section{Key Words}

Skin prick test $\cdot$ Allergen $\cdot$ Histamine $\cdot$ Dose response .

Parallel line bioassay · Threshold concentration · Proficiency test

\begin{abstract}
Background: The allergen dose-response curve is flat; thus, small changes in wheal size reflect large differences in skin sensitivity. The sensitivity as measured by provocation tests is given by the threshold concentration that causes symptoms and/or objective signs. The threshold concentrations differ by several magnitudes between the most and the least sensitive individuals clinically allergic to the same allergen. Variation in technique can be minimized by relating allergen responses to that to histamine. The aim here is to present and validate simple methods for estimation of the skin sensitivity given as the concentration inducing a wheal of the same size as that with the positive reference, $10 \mathrm{mg} / \mathrm{ml}$ of histamine $\mathrm{HCl}$, in the same patient. Methods: Data from previously reported trials on the biological equilibration of allergen extracts were used to document a method to calculate the concentration of allergen required to induce a wheal of the same size as that with $10 \mathrm{mg} / \mathrm{ml}$ of histamine dihydrochloride in the same patient, and to validate the methods using the parallel line bioassay as the gold standard. Results: The validated methods correlated well with the results ob-
\end{abstract}

tained using the gold standard method and provide results of skin prick testing based on threshold concentrations of allergen. Conclusions: The validated methods reduce the error of differences in testing techniques and make it possible to report skin sensitivity at threshold concentrations. A simple method to be used in clinical practice and a method suitable to describe changes in skin reactivity over time or during treatment are proposed.

(c) 2015 S. Karger AG, Basel

\section{Introduction}

Until the skin prick test (SPT) was accepted in Europe as the method for routine diagnosis of sensitization and skin reactivity, most allergists used the endpoint concentration by intradermal skin titration as a measure of skin reactivity. However, from the 1970s, manufacturers provided extracts for the SPT in one concentration, i.e. for use in clinical practice, and even scientific reports did not include endpoint concentrations but rather wheal sizes, using one and the same concentration of allergen in all patients. Thus, the results of SPTs

Margareta Holgersson sadly deceased in the course of the preparation of this paper in 2013.

\section{KARGER 125}

(c) 2015 S. Karger AG, Base

$1018-2438 / 15 / 1661-0071 \$ 39.50 / 0$

E-Mail karger@karger.com

www.karger.com/iaa
Correspondence to: Prof. Sten Dreborg

Department of Women's and Children's Health

Department of Pediatric Allergology, Uppsala University Hospital

SE-751 85 Uppsala (Sweden)

E-Mail sten.dreborg@kbh.uu.se 
have been reported as the wheal diameter in millimeters, the wheal area in millimeters squared, or according to the semi-quantitative +++ system devised by Aas and Belin [1]. Thus, SPT results are not comparable to results from bronchial, oral, nasal or conjunctival provocation tests, where results are reported as threshold concentrations.

In a random sample, threshold concentrations differ more than 4 -fold between the least and most sensitive patients. Threshold concentrations are log distributed [24]. The flat allergen wheal dose response means that a 10 -fold increase in skin sensitivity corresponds roughly to an increase in wheal diameter from 3 to $4.65 \mathrm{~mm}$, or from 4.65 to $7.2 \mathrm{~mm}$ in diameter, etc. [5]. Thus, wheals 3 and $11 \mathrm{~mm}$ in diameter represent a 1,000-fold difference in sensitivity.

Since 1973, the simple +++ method of Aas and Belin [1] comparing the allergen wheal size in relation to that with histamine has been widely used. Histamine reactivity represents the general skin reactivity that is correlated to the degree of sensitization [6]. However, the method is semiquantitative and has never been thoroughly documented.

Adjusting the allergen skin test with the histamine reactivity in the same patient eliminates the influence of differences in SPT technique [7]. Thus, it would be of value to be able to find a simple, practically applicable method to equalize the allergen wheal response between testing personnel. Furthermore, it would be of value to be able to express the response to allergen as a threshold concentration, comparable to provocation tests in other organs [2-4].

The aim of the present study is to validate simplified methods of estimating skin sensitivity to allergens in relation to that to histamine. These results are compared to those using the gold standard estimation of the concentration of allergen comparable to that of histamine, the parallel line bioassay. Finally, we wish to present some simple methods available for allergy practices and clinical research.

\section{Materials and Methods}

\section{Patients}

The patient samples investigated have been presented previously [4, 8]. Briefly, 36 wall pellitory-sensitive patients [8] and 26 mite-sensitive patients [4] from previously published papers on the biological equilibration of allergen extracts were included consecutively, i.e. without any selection. The mean age of the patients sensitive to wall pellitory (Parietaria officinalis) was 31.5 years (range 15-49), and that of the mite-sensitive patients was
32 years (range 17-45). The inclusion criteria were a clinical history of wall pellitory or possible mite respiratory allergy; a positive SPT with wall pellitory extract ( $P$. officinalis and $P$. judaica) or Dermatophagoides pteronyssinus and $D$. farinae allergen extracts, respectively; a histamine wheal $(1 \mathrm{mg} / \mathrm{ml})$ at least $\geq 4 \mathrm{~mm}$ in diameter; never having received allergen-specific immunotherapy; the allergen investigated being an adequate problem in the region; being aged 15 years or older, and not having taken antiallergic drugs for a period adequate to avoid an influence on the skin test results [9]. The local ethics committees approved the original trials $[4,8]$.

\section{Test Solutions}

Freeze-dried, standardized allergen preparations of wall pellitory (P. officinalis; batch D 821216/2, 18\% protein) [8] and house dust mite (D. pteronyssinus; batch D $820421 / 2$, 44\% protein) [4] were used (in-house references; Pharmacia Diagnostics AB, Uppsala, Sweden). The extracts were purified by removal of low-molecular-weight substances by ultrafiltration. The freeze-dried extracts were reconstituted on the day of testing with Albumin Diluent ${ }^{\circledR}(0.03 \%$ human serum albumin and $0.4 \%$ phenol in saline; Pharmacia Diagnostics AB). Histamine dihydrochloride $1 \mathrm{mg} / \mathrm{ml}$ ( $5.43 \mathrm{mmol} / \mathrm{l}$ or $0.63 \mathrm{mg} / \mathrm{ml}$ histamine base; Pharmacia Diagnostics $\mathrm{AB})$ and histamine dihydrochloride $10 \mathrm{mg} / \mathrm{ml}(54.3 \mathrm{mmol} / \mathrm{l}$ or $6.3 \mathrm{mg} / \mathrm{ml}$ histamine base, Pharmacia Diagnostics AB) were used. The potency of the extracts is given in dry weight per milliliter, which is the most exact method for dispensing allergen extracts for final production.

\section{SPT Method}

The method described by Østerballe and Weeke [10] was employed, using a steel lancet with a 1-mm tip and shoulders to prevent the lancet from further penetration of the skin. The tip was pressed at a 90-degree angle against the skin surface through a drop of allergen or histamine, applying the same pressure each time. One lancet was used per test. After completion of the test, the test solution remaining on the skin surface was removed by pressing a soft tissue against the skin. In principle, the criteria set up in the EAACI position paper on skin testing [11] were followed: after 15 min, wheals were encircled on the surrounding erythema, the drawing was transferred by means of a translucent tape to a record sheet, and the area was estimated by a digitizer.

\section{Original Test for Biological Equilibration}

The original trials were performed as part of a pan-European effort to document the equilibration of the total allergenic potency of common inhalant allergen extracts. To obtain similar samples of patients, the above inclusion criteria were followed in all such published trials $[3,4,8,12-14]$.

\section{Design}

First, a preliminary test was performed on the volar aspect of the forearm to decide upon the three concentrations to be used in the final test on the back. Due to the poor precision of the SPT [4], several parallel tests with the same concentration were needed to define the response to each concentration and to estimate the doseresponse relationship by parallel line bioassay within each patient. The dose response was best fitted to the model: $\log \mathrm{D}$ or $\mathrm{A}=\mathrm{a}+\mathrm{b}$ $\log \mathrm{C}$, within the normal range of wheal sizes obtained by the SPT, where $\mathrm{A}$ is area, $\mathrm{D}$ is diameter and $\mathrm{C}$ is concentration. The allergen 


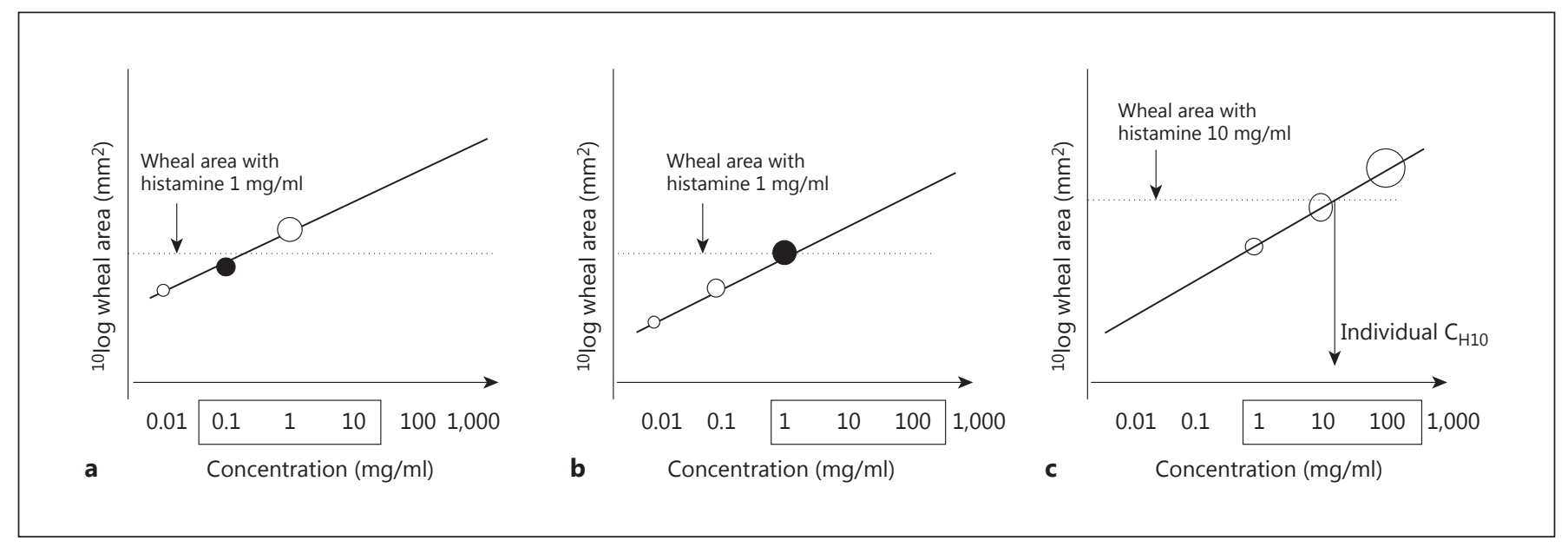

Fig. 1. Original test procedure $[4,15]$. The pretest on the forearm is performed using duplicate tests with the three lowest of six 10fold concentrations. The horizontal line denotes the mean wheal diameter obtained with $1 \mathrm{mg} / \mathrm{ml}$ of histamine in the same patient $\left(\mathrm{D}_{\mathrm{H} 1}\right)$ or the mean wheal area obtained with $1 \mathrm{mg} / \mathrm{ml}$ of histamine in the same patient $\left(\mathrm{A}_{\mathrm{H} 1}\right)$. The slope represents the allergen dose response, and the rings the mean wheal responses to the three lowest concentrations of the test solution, respectively. The filled circles indicate the concentration $(\mathrm{C})$ eliciting a mean wheal diameter $\left(D_{A}\right)$ or mean wheal area obtained with the same allergen concentration in the same patient $\left(\mathrm{A}_{\mathrm{A}}\right)$ of similar size as that with $\mathrm{D}_{\mathrm{H} 1}$ or $\mathrm{A}_{\mathrm{H} 1}$, and the rectangles indicate the three concentrations chosen

concentrations causing wheals similar in size to that caused by 10 $\mathrm{mg} / \mathrm{ml}$ of histamine $\mathrm{HCl}\left(\mathrm{C}_{\mathrm{H} 10}\right)$ in the same patient, and concentrations 10 times lower and higher than that, were selected for the final test on the back $[4,8,15]$.

Test Solutions

The stock solution (approx. $1 \mathrm{mg}$ protein/ml) was prepared by reconstitution of the freeze-dried reference extract with Albumin Diluent and then five 10-fold dilutions of the stock solution were prepared on the day of testing [4].

Preliminary Test on the Volar Aspect of the Forearm

The preliminary test on the volar aspect of the forearm was performed in duplicate with the three lowest concentrations of the test extract and $1 \mathrm{mg} / \mathrm{ml}$ of histamine $\mathrm{HCl}\left(\mathrm{C}_{\mathrm{H} 1}\right)$. The concentration eliciting a wheal of similar size as that with $\mathrm{C}_{\mathrm{H} 1}$ was identified (fig. 1a, b).

If the concentrations used in all three preliminary tests were smaller than that of $\mathrm{C}_{\mathrm{H} 1}$, then the three highest concentrations were used. The reason for using six concentrations of allergen to be tested was that, in preliminary trials, the difference in skin sensitivity between patients with clinical symptoms attending specialized clinics varied by more than four magnitudes $[4,8,12,14]$. Therefore, first the concentration eliciting a wheal of approximately the same size as that of $\mathrm{C}_{\mathrm{H} 10}$ was identified. That concentration, the concentrations 10 times higher and 10 times lower and $\mathrm{C}_{\mathrm{H} 10}$ for the final test on the back. a The $\mathrm{D}_{\mathrm{A}}$ or $\mathrm{A}_{\mathrm{A}}$ elicited by the middle $\mathrm{C}_{\mathrm{A}}$ tested was of similar size as that with $\mathrm{D}_{\mathrm{H} 1}$ or $\mathrm{A}_{\mathrm{H} 1}$ and, therefore, was chosen as the lowest $C_{A}$ tested in the final test. $b$ The $D_{A}$ or $A_{A}$ elicited by the highest $C_{A}$ tested was closest to the size of that with $\mathrm{D}_{\mathrm{H} 1}$ or $\mathrm{A}_{\mathrm{H} 1}$, and, therefore, this and two higher allergen concentrations were tested in the final test on the back. $\mathbf{c}$ The $\mathrm{C}_{\mathrm{A}}$ chosen in the pretest and two higher concentrations were tested in quadruplicate on the back, i.e. 12 SPTs with allergen and 4 with $\mathrm{C}_{\mathrm{H} 10}$ in total. The concentration eliciting a wheal of the same size as that with $\mathrm{C}_{\mathrm{H} 10}$ in the same patient at the same time is calculated according to the model ${ }^{10} \log \mathrm{A}=\mathrm{a}+{ }^{10} \log \mathrm{C}$.

were tested in quadruplicate in the final test on the back. This procedure assures that the allergen concentration eliciting a wheal of the same size as that with $\mathrm{C}_{\mathrm{H} 10}$ could be calculated by parallel line bioassay using approximately the same part of the slope of the allergen dose response (fig. 1c).

Definite Test on the Back

The concentration of allergen inducing a wheal reaction similar to that with $\mathrm{C}_{\mathrm{H} 1}$, the allergen dilutions 10 and 100 times stronger as well as $\mathrm{C}_{\mathrm{H} 1}$ and $\mathrm{C}_{\mathrm{H} 10}$ were all tested in quadruplicate, allocated on the back in a mirrored pattern (fig. 1c).

\section{Methods for Evaluation in This Study}

The Published Method for Biological Equilibration

The geometric mean of the four tests with $\mathrm{C}_{\mathrm{H} 10}$ and each of the three individually selected concentrations of allergen were used for further calculations in the published reports [4].

In preliminary trials $[12,14,16]$, the dose response of allergen skin test reactivity within the response level used for the SPT had been found to be best fitted to the $\log / \log$ model: $\log \mathrm{A}=\mathrm{a}+\mathrm{b} \log \mathrm{C}$.

The four tests with $\mathrm{C}_{\mathrm{H} 10}$ and the four allergen tests were performed with each concentration of allergen allocated over both sides of the back, in a mirrored, upside-down manner. The allergen concentration eliciting a wheal of the same size as that with $\mathrm{C}_{\mathrm{H} 10}$ in the individual patient was estimated by parallel line bioassay (fig. 1c). 
Fig. 2. The method of Björkstén et al. [16]. a The original method used one test with one $\mathrm{C}_{\mathrm{A}}$ and one test with $\mathrm{C}_{\mathrm{H} 1}$. An individual 'HEP' (or $\mathrm{C}_{\mathrm{H} 1}$ ) was calculated using the formula: individual HEP $=[D h / D a]^{5.07}$; $\mathrm{b}$ was found to be 0.198 and, thus, the index was 5.07 using one of the wheals indicated by the filled circles. b Our modification used either one or four tests with one concentration. Patients reacted with either a wheal smaller than the histamine wheal, the black dot, or with a wheal larger than the histamine wheal, the circle filled gray that was used for calculations of $\mathrm{C}_{\mathrm{H} 10}: \mathrm{C}_{\mathrm{H} 10}=[A a / A h]^{2.5} \times \mathrm{C}$.

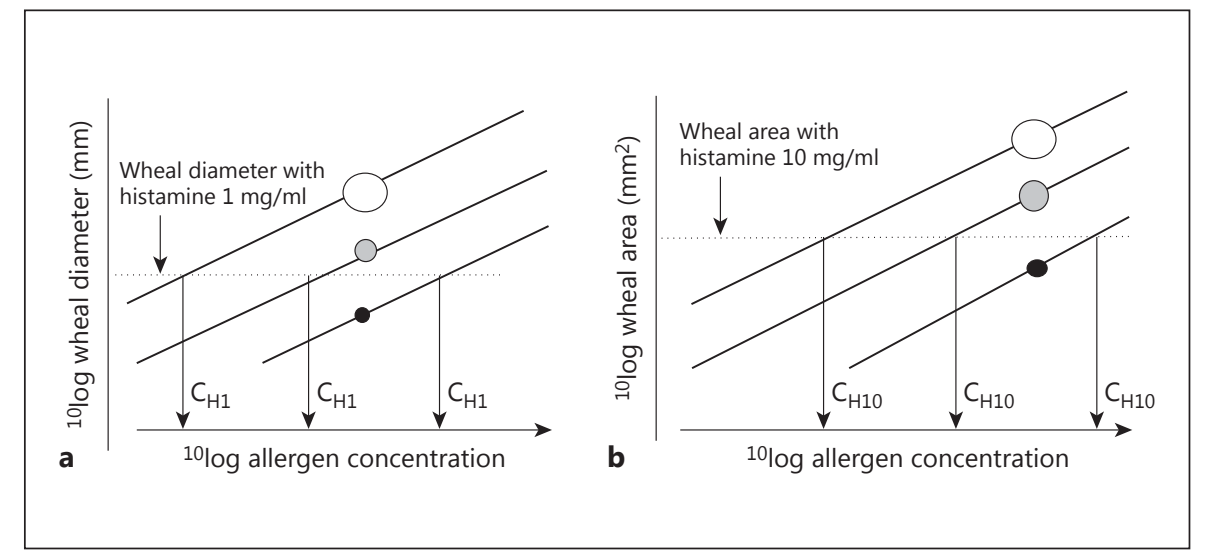

In this study, we used either four tests obtained with the three selected allergen concentrations or one test per concentration, selected at random, to estimate $\mathrm{C}_{\mathrm{H} 10}$ in the individual patient, using the model: $\log \mathrm{A}=\mathrm{a}+\mathrm{b} \log \mathrm{C}$. The results are given in micrograms dry weight per milliliter, the geometric mean, the $95 \% \mathrm{CI}$ and the range.

The method using four parallel tests that was originally published in 1987 [4] was later adopted by the Nordic Council on Medicines and included in an appendix of the second edition of the Nordic guidelines on allergen standardization [15].

The Original Method of Björkstén et al.

Originally, Björkstén et al. [16] used a single test with one concentration of allergen and histamine of $1 \mathrm{mg} / \mathrm{ml}$, respectively. In a preliminary study, they found the best-fitted model was a log-log model: $\log \mathrm{D}=\mathrm{a}+\mathrm{b} \log \mathrm{C}$.

In this study, we used the same model but chose the concentration with which most patients had been tested in the original trial [4]. Since we had calculated the areas, the model used was: $\log \mathrm{A}=$ $\mathrm{a}+\mathrm{b} \log \mathrm{C}$.

The method of Björkstén et al. [16] and its principles are shown in figure 2a. The proposed method for clinical use is available in online supplementary Appendix 1 (for all online suppl. material, see www.karger.com/doi/10.1159/000366203).

The Modified Method of Björkstén et al.

Either one or four tests with one concentration of three tested, with a (mean) wheal size most similar to that with $\mathrm{C}_{\mathrm{H} 10}$, were used for estimating the $\mathrm{C}_{\mathrm{H} 10}$, using the area of the wheal(s) and the loglog model (see fig. 2b and online supplementary Appendix 2 for further details):

$$
\mathrm{C}_{\mathrm{H} 10}=[A h / A a]^{2.5} \times \mathrm{C}_{\mathrm{A}},
$$

where $\mathrm{C}_{\mathrm{A}}$ is the concentration of allergen. In both these simplified methods, when using a single test concentration, the test utilized was chosen at random by noninvolved personnel among the four allergen tests.

Proposed Single-Concentration Methods

The proposed methods presented are as follows: (1) in allergy practices, use the diagnostic allergen extract normally used in the practice, i.e. a single fixed concentration of allergen and $\mathrm{C}_{\mathrm{H} 10}$ (on- line suppl. Appendix 1), and (2) in scientific work, a limited titration with 10 -fold concentrations of allergen and $\mathrm{C}_{\mathrm{H} 10}$ (online suppl. Appendix 2).

\section{Results}

All patients fulfilling the inclusion criteria used in this paper who participated in the original wall pellitory and mite trials, which aimed at determining the biological activity of partly purified wall pellitory ( $P$. officinalis) and mite (D. pteronyssinus) allergen extracts, were included in the evaluations. The results of the wall pellitory and mite individual $\mathrm{C}_{\mathrm{H} 10}$ and median $\mathrm{C}_{\mathrm{H} 10}$ concentrations using the three different methods are shown in figure $3 \mathrm{a}$ and $b$. The $95 \%$ CI of the reference parallel line bioassay method overlapped that of the unmodified and modified methods of Björkstén et al. [16], using one or four tests. Thus, all showed similar $\mathrm{C}_{\mathrm{H} 10}$ and geometric means as the parallel line bioassay, i.e. the gold standard. The concentration of allergen eliciting a wheal of the same size as that with $\mathrm{C}_{\mathrm{H} 10}$ can therefore be estimated by using one concentration of histamine and one concentration of allergen.

\section{Discussion}

It has been shown that relating the allergen SPT wheal response to that to histamine in the same patient reduces the main drawback of the SPT method, i.e. the difference in technique between testing personnel. Thus, the significance of the technique used by the technician is largely eliminated [7]. 


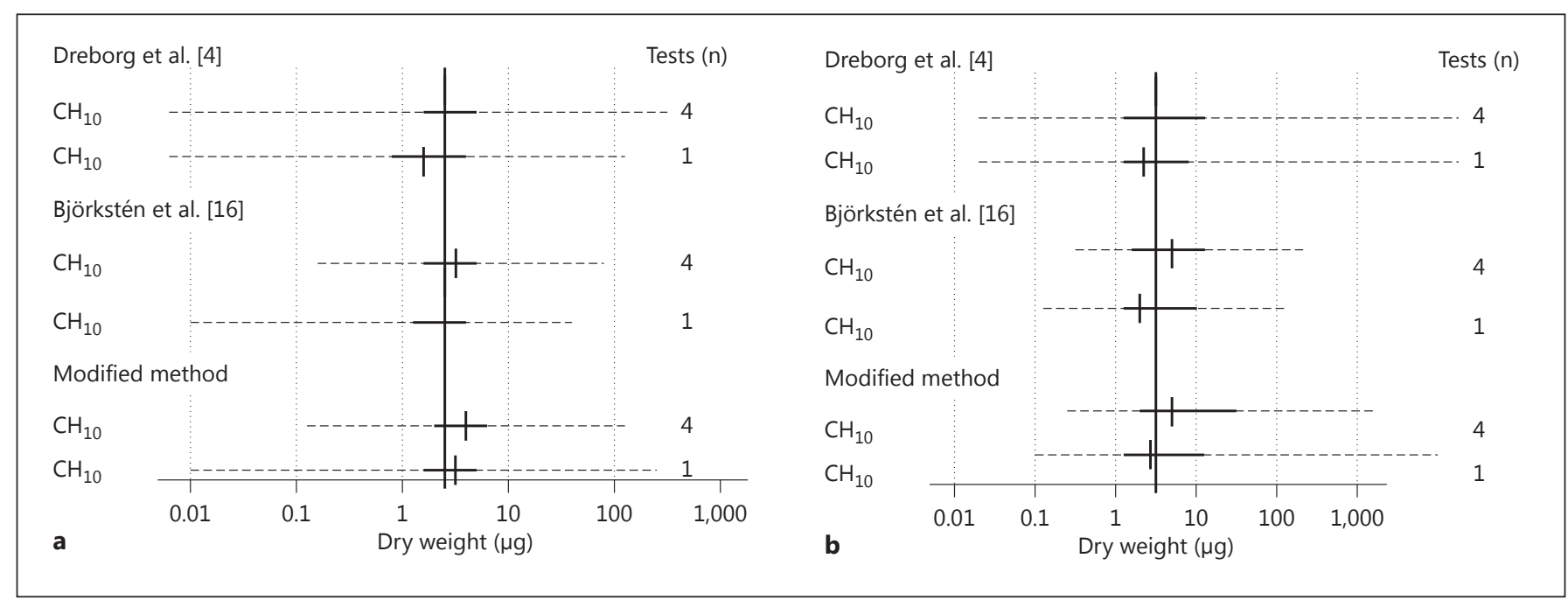

Fig. 3. The distribution of individual $\mathrm{C}_{\mathrm{H} 10}$ showing the range, confidence limits and median in each case. a Wall pellitory (P. officinalis). b House dust mite (D. pteronyssinus).

This paper shows that a formula can be derived by using the common slope of the log-log allergen doseresponse relationship: ${ }^{10} \log \mathrm{D}$ or $\mathrm{A}=\mathrm{a}+\mathrm{b}{ }^{10} \log (\mathrm{C})$. The concentration eliciting a wheal the same size as that with $10 \mathrm{mg} / \mathrm{ml}$ of histamine dihydrochloride can be calculated by: $[D h / D a] 1 / b \times C$ used, where $\mathrm{b}=0.20$ for the diameter or 0.4 for the area. Therefore, the index $(1 / 0.2)$ is equal to 5 , or simply $[D h / D a]^{5} \times \mathrm{C}$ used, or for the area $(1 / 0.4)$, it can alternatively be presented as $[\mathrm{Dh} / \mathrm{Da}]^{2.5} \times \mathrm{C}$. Using the mean $b$ found [4], 0.387 (95\% CI 0.371-0.403) for the allergen and 0.334 (95\% CI $0.332-0.357)$ for histamine, respectively, the index when calculating with the area should be 2.58 and 2.99 , respectively. Strictly, the formulas shown are not valid, since the dose-response curves are not totally parallel. However, at least when using allergen wheals of a similar size as that with histamine, the above approximation can be accepted, as has been shown in this paper.

Of the two simple methods, the original method proposed by Björkstén et al. [16] (online suppl. Appendix 1) is recommended for use in clinical practice. In scientific work, the alternative method (online suppl. Appendix 2) may be preferred, despite the fact that the results do not differ when the two methods are applied to groups.

The proposed methods express skin reactivity in the form of threshold concentrations. The threshold concentration is a better indicator of reactivity than the diameter or area when trying to ascertain the skin response. It is also more suitable when comparing skin response to that of other organs, i.e. the conjunctiva, the nasal mucosa, bronchi and the gastrointestinal tract, the reactivities of which are always reported as threshold concentrations.

The benefit from using the methods described in the appendices is that the skin response is expressed as the threshold concentration. Threshold concentrations make it possible to express the skin sensitivity of patients in a concentration of allergen. Differences in threshold concentration are better estimates of the skin sensitivity between patients and within patients over time than are changes in wheal size.

At least duplicate tests should be used to document the coefficient of variation of the SPT in the hands of the testing personnel. In small children, regular proficiency testing and single tests can be accepted. It is essential to use a proficiency test program, thus assuring constant, reproducible results [17].

\section{The Methods Proposed}

The principles behind the methods that have been proposed in this paper can be summarized as follows:

- differences in technique should be compensated for by referring the allergen response to that to histamine;

- skin reactivity should be expressed as a threshold concentration, making it possible to express differences in skin reactivity between centers and within patients over time in terms of allergen concentration;

- consequently, comparison of skin test reactivity between centers in, for example, epidemiological stud- 
ies and multicenter therapeutic studies becomes possible.

These methods will be validated in a forthcoming paper in relation to other methods in their ability to evaluate changes in skin sensitivity during treatment [Dreborg et al., submitted].

\section{Acknowledgements}

My sincere thanks to Dr. Antonio Basomba (Valencia), to Profs. Barry Kay, Tak Lee and Steven Durham (London) as well as to their nurses, who did the original skin testing. Thanks are also due to Margareta Holgersson, $\mathrm{PhD}$, who gave statistical advice, and the statistician Anders Hansson, MSc, who did the computer work.

This work has not been published as an original paper but is a nonpublished part of paper IV in the medical dissertation by Dreborg [3].

\section{Disclosure Statement}

No financial support was provided for this publication. The biological standardization/equilibrating trials and the statistical work done 25 years ago was supported by Pharmacia Diagnostics $\mathrm{AB}$, Uppsala, Sweden.

\section{References}

1 Aas K, Belin L: Northern (Scandinavian) Society for Allergology: standardization of diagnostic work in allergy. Acta Allergol 1974;29: 239-240.

2 Dreborg S: Bronchial provocation tests with biologically standardised allergenic preparations; in Melillo G, Norman PS, Marone G (eds): Clinical Immunology. Philadelphia, CW Decker, 1990, pp 185-191.

3 Dreborg S: The skin prick test: methodologicalstudies and clinical applications; Linköping University Medical Diss No 239, 1987.

4 Dreborg S, Basomba A, Belin L, Durham S, Einarsson R, Eriksson NE, et al: Biological equilibration of allergen preparations: methodological aspects and reproducibility. Clin Allergy 1987; 17:537-550.

5 Dreborg S: Skin testing in allergen standardization and research; in Dolen W (ed): Skin Testing. Philadelphia, WB Saunders, 2001,pp 329-354.

6 Stuckey M, Witt C, Schmitt L, Warlow R, Lattimore M, Dawkins R: Histamine sensitivity influences reactivity to allergens. J Allergy Clin Immunol 1985;75:373-376.
7 Dreborg S: Allergen skin prick test should be adjusted by the histamine reactivity. Int Arch Allergy Immunol 2015;166:77-80.

8 Dreborg S, Basomba A, Einarsson R: Sensitivity to Parietaria officinalis and Parietaria judaica pollen allergens in a Spanish population. Allergol Immunopathol 1986;14:499508.

9 Pipkorn U: Pharmacological influence of antiallergic medication on in vivo allergen testing. Allergy 1988;43:81-86.

$10 \varnothing$-sterballe O, Weeke B: A new lancet for skin prick testing. Allergy 1979;34:209-212.

11 Dreborg S, Frew A: Position paper: allergen standardisation and skin tests. Allergy 1993; 47(suppl 14):48-82.

12 Dreborg S, Grimmer O: Biological standardization of allergen extracts/preparations. Arb Paul Ehrlich Inst Georg Speyer Haus Ferdinand Blum Inst Frankfurt AM 1983;78:7782.
13 Dreborg S, Sjogren I, Eriksson NE, Einarsson R: Selection of patients for biological standardization as exemplified by standardization of mugwort, goosefoot and English plantain pollen allergen extracts/preparations. Allergy 1987;42:485-495.

14 Dreborg S, Belin L, Eriksson NE, Grimmer O, Kunkel G, Malling HJ, et al: Results of biological standardization with standardized allergen preparations. Allergy 1987;42:109116.

15 Nordic Council on Medicines: Guidelines for registration and standardization of allergenic extracts. NLN Publication No. 23. Uppsala, Nordic Council on Medicines, 1989, ed 2, pp $1-48$.

16 Björkstén F, Haahtela T, Backman A, Suoniemi I: Assay of the biological activity of allergen skin test preparations. J Allergy Clin Immunol 1984;73:324-331.

17 Proficiency testing: Allergy skin testing https://aaaai.confex.com/aaai/2013/ webprogramhandouts/Session1315.html (accessed February 22, 2013). 